\title{
EFEITO DE LINHAGENS COM CARACTERÍSTICAS MORFOLÓGICAS MUTANTES SOBRE O BICUDO E A PRODUÇÃO DO ALGODOEIRO
}

\author{
D. Gabriel; F.M.G. Blanco
}

${ }^{1}$ Instituto Biológico, Centro Experimental Central, CP 70, CEP 13001-970, Campinas, SP, Brasil. E-mail: dalva@biologico.sp.gov.br

\section{RESUMO}

\begin{abstract}
O presente trabalho objetivou avaliar linhagens de algodoeiro com características morfológicas mutantes quanto à infestação pelo bicudo Anthonomus grandis Boheman e suas produções. $\mathrm{O}$ experimento foi conduzido em campo, com a cultivar IAC-24 (testemunha), IAC-04/227 (planta vermelha) e IAC-04/489 (folha "okra"). A infestação foi avaliada contando os botões florais perfurados para a alimentação e oviposição do bicudo. A produção foi avaliada pelo do rendimento de algodão. A linhagem IAC-04/227 diferiu da cultivar IAC-24 e da linhagem IAC04/489 até 85 dias após a emergência das plântulas, apresentando menor porcentual de botões florais perfurados pelo bicudo. Este fato indica que a coloração vermelha das plantas é um caráter importante no manejo da resistência do algodoeiro ao bicudo. Não houve diferença significativa, entre os genótipos, para o rendimento de algodão, mas para a massa de 100 sementes, a cultivar IAC-24 diferiu da linhagem IAC-04/227, apresentando a maior média.
\end{abstract}

PALAVRAS-CHAVE: Gossypium hirsutum, Anthonomus grandis, folha "okra", planta vermelha.

\section{ABSTRACT}

EFFECTS OF COTTON LINES WITH MUTANT MORPHOLOGICAL CHARACTERS ON THE BOLL WEEVIL AND YIELD. This study was aimed at evaluating cotton lines with morphological mutantcharacters in regard to the boll weevil Anthonomus grandis Boheman and yield. Theexperiment was performed under field conditions with IAC-24 (control), IAC-04/227 (red plant) and IAC-04/489 (okra leaf). The boll weevil infestation was evaluated by counting damaged squares (feeding and egging punctures) and the yield through cotton-boll production. IAC-04/227 varied from IAC-24 and IAC-04/ 489 until 85 days after outgrowth, presenting a lower percentage of punctured squares by boll weevils. This fact indicates that the red color of the plants is an important character for resistance to the boll weevil. There was no significant difference between the cotton lines in terms of yield, but in terms of the weight of 100 seeds the IAC-24 presented a higher average than the IAC-04/227.

KEY WORDS: Gossypium hirsutum, Anthonomus grandis, okra leaf, red plant.

\section{INTRODUÇÃO}

A cultura do algodoeiro tornou-se uma das principais fontes de sustentação da economia em algumas regiões, ocupando parte das áreas mais férteis de outras culturas tradicionais como a soja e o milho.

Osucesso na produção de qualquer cultura, especialmente do algodoeiro, depende fundamentalmente da escolha correta da variedade a ser cultivada, do ambiente onde a cultura vai crescer e do manejo cultural a ser empregado.

As pragas ocupam lugar de destaque entre os diversos problemas enfrentados pela cotonicultura, principalmente o bicudo por se tratar da praga chave e encontrar-se amplamente disseminado em todas as regiões produtoras.
A investigação sobre cultivares de algodoeiro, resistentes às pragas, teve início no princípio do século $\mathrm{XX}$, com as primeiras descobertas de características morfológicas mutantes. Os estudos genéticos realizados com os caracteres folha "okra", bráctea frego e planta vermelha demonstraram que eram herdados monogeneticamente e podiam ser facilmente manipulados e introduzidos em novas bases genéticas, para estudos de resistência (Jones et al., 1986).

O primeiro caráter, reconhecido como um fator de resistência ao bicudo, foi a coloração vermelha da planta $\left(\mathrm{R}_{1}\right)$, de dominância incompleta eque se baseia no mecanismo de não- preferência para alimentação (WeAver JúNior; RedDy, 1977).

O mutantefolha "okra" $\left(\mathrm{L}_{2}^{\circ}\right)$ apresenta dominância incompleta em relação à folha normal $\left(1^{\circ}\right)$ e tem por 
característica folhas profundamente recortadas, que permite maior penetração de luz solar, aumentando a mortalidade dos imaturos, além de permitir maior penetração dos inseticidas, aumentando sua eficiência sobre os adultos (Jones et al., 1986).

O objetivo deste trabalho foi avaliar linhagens de algodoeiro, desenvolvidas pelo Instituto Agronômico de Campinas (IAC), que apresentam, isoladamente, as características morfológicas mutantes, planta vermelha e folha "okra", quanto à infestação pelo bicudo, bem como avaliar suas produções a fim de contribuir com os programas de melhoramento que buscam resistência a esta importante praga do algodoeiro.

\section{MATERIAL E MÉTODOS}

O material genético utilizado constou de duas linhagens, IAC-04/227 e IAC-04/489 e, da cultivar IAC-24 (testemunha). A linhagem IAC-04/227, que é resultado de cruzamento da linhagem Texas Red e da linhagem IAC- 87/544, apresenta plantas de coloração vermelha efolha normal. A linhagem IAC-04/ 489 apresenta plantas de coloração verde e folha "okra". A cultivar IAC-24 apresenta plantas de coloração verde e folha normal.

O experimento para avaliação destas linhagens, quanto à infestação pelo bicudo e de sua produção, foi conduzido em campo, sob infestação natural, no Centro Experimental Central do Instituto Biológico, em Campinas, SP, na safra 2005/2006. Adotou-se delineamento estatístico de blocos ao acaso, com 8 repetições.

As parcelas constaram de uma fileira de $3 \mathrm{~m}$ de comprimento, espaçadas de $1 \mathrm{~m}$, com 8 plantas por metro linear. A semeadura ocorreu em 24/10/ 2005. A adubação foi realizada com NPK (4-14-8) na época da semeadura e com sulfato de amônia, em cobertura, 30 dias após semeadura. Não foi realizado qualquer controle de pragas e as plantas daninhas foram controladas por meio de capinas manuais.

As avaliações foram feitas, semanalmente, a partir de 3/1/2006, aos 64 dias após emergência das plântulas (DAE) e término em 21/2/2006 (113 DAE), econstaram do exame de 20 botões florais por parcela, 1 botão floral por planta, para identificação de orifícios de alimentação e oviposição feitos pelo bicudo. Durante o período experimental foram realizados oito levantamentos.

Para a avaliação da produção foram colhidos os capulhos produzidos em cada parcela, a seguir foram contados e pesados. Foram avaliados os seguintes parâmetros: número de capulho por planta, rendimento de algodão em caroço por planta, massa de 1 capulho e de 100 sementes, porcentagem de fibra e de germinação das sementes.

Os dados da porcentagem de botões florais atacados pelo bicudo foram analisados após transformação em arc sen $\sqrt{x+1}$, tendo sua variância sido analisada pelo teste F (1 \% e 5\%). Os dados da produção foram analisados após transformação em $\sqrt{x+1}$ (número de capulhos por planta) e arc sen ( $\%$ de fibra e \% de germinação de sementes) e para os parâmetros avaliados em que o $\mathrm{F}$ foi significativo, realizou-se o teste de médias (Tukey, 5\%).

\section{RESULTADOS E DISCUSSÃO}

No período compreendido entre 64 e 85 dias após a emergência (DAE) do algodoeiro, a linhagem IAC04/227 (planta vermelha e folha normal) diferiu significativamente, a $5 \%$ de probabilidade pelo teste de Tukey, da cultivar IAC-24 (planta verde e folha normal) e da linhagem IAC-04/489 (planta verde e folha "okra"), apresentando as menores médias para a porcentagem debotões florais danificados pelobicudo (Fig. 1).

Resultado semelhante foi obtido por IsELy (1928) que verificou que a variedade de algodão de coloração vermelha, Winesap, apresentou cerca de metade dos danos dos que ocorreram em duas variedades de coloração verde, em testes comparativos, em Arkansas.

Vidal Neto et al. (2005) avaliaram mutantes morfológicos de algodoeiro como fonte de resistência ao bicudo e concluíram que a característica mutante planta vermelha é a segunda mais promissora para redução da população do bicudo, figurando como primeira, a bráctea frego, não avaliada no atual trabalho e, quanto à característica mutante folha "okra" estes autores concluíram que o efeito só se manifesta quando associada à bráctea frego.

GABRIEL et al. (2005) avaliaram a não preferência do bicudo do algodoeiro para a cultivar IAC-24 (planta verde) e a linhagem IAC-04/227 (planta vermelha) e concluíram que esta é menos preferida para a alimentação e oviposição do bicudo, do que a cultivar IAC-24, quando cultivadas na mesma área.

Merkl; Meyer (1963) estudaram a resistência, ao bicudo, de linhagens com caracteres diversos e concluíram que, havendo chance de escolha, os bicudos preferem plantas verdes, mas se estas não estiverem disponíveis podem ter sucesso em plantas vermelhas. Estes autores também verificaram que a linhagem pubescente e com folha "okra" teve baixa porcentagem de botões florais perfurados, mas sob condições de baixa pressão populacional do inseto, fato este não verificado no transcorrer deste trabalho. 


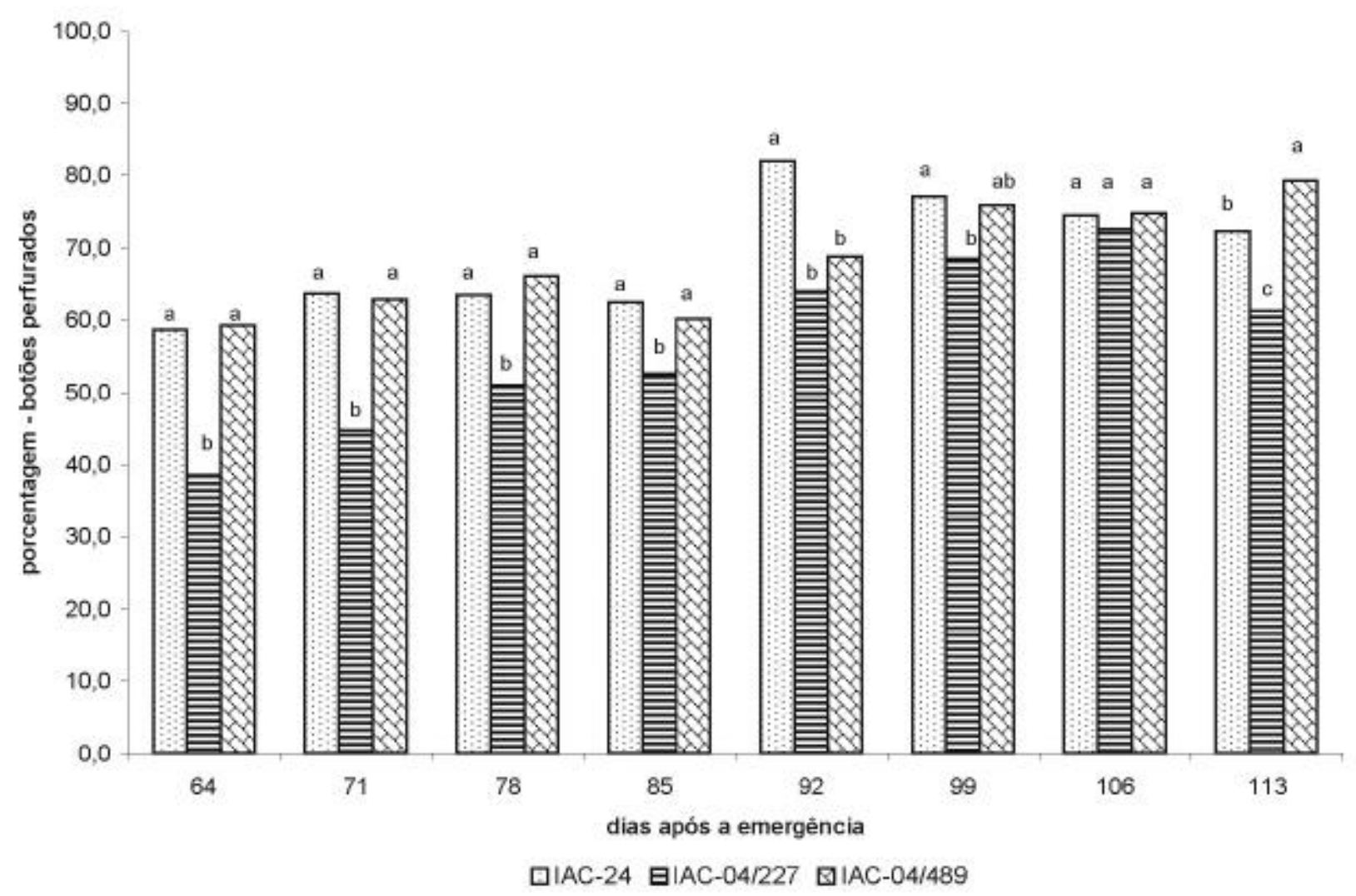

Fig. 1 - Médias das porcentagens de botões florais perfurados por A. grandis para diferentes genótipos de algodoeiro. Campinas, SP. 2006.

De acordo com CRuz (1991), o nível de controle para o bicudo, no período compreendido entre a abertura da $1^{\mathrm{a}}$. flor e $110 \mathrm{DAE}$, é de $10 \%$ de botões florais perfurados. Nas condições do experimento, sem o controle do bicudo, a menor média para a porcentagem de botões florais atacados $(38,5)$ foi verificada para a linhagem IAC-04/227, aos 64DAE, enquanto que para o mesmo período a cultivar IAC24 e a linhagem IAC-04/489 apresentaram, respectivamente, 58,7 e 59,2 (Fig. 1). Com estes resultados pode-se inferir que em condições de cultivo comercial, com o controle desta praga, a linhagem IAC-04/ 227 teria como vantagens aplicação mais tardia e menor número de pulverizações com inseticidas, corroborando os resultados de MerkL; Meyer (1963) que verificaram menor e mais tardia infestação na linhagem vermelha dentre os diferentes genótipos avaliados.

Testes de laboratório conduzidos por STEPHENS; Lee (1961) e confirmados por MerkL; Meyer (1963) indicaram que botões florais de coloração vermelha, quando encontrados, não são desprezados pelo bicudo. Esta constataçãoe explica o comportamento da linhagem IAC-04/227 (planta vermelha) que, aos 92, 99 e 106 DAE, não diferiu da linhagem IAC-04/ 489 (planta verde), mas diferiu desta aos 113 DAE. A
linhagemIAC-04/227 também não diferiu da cultivar IAC-24 (planta verde) aos 106 DAE, mas diferiu desta, aos 113 DAE (Fig. 1).

Aos 106 DAE não foi constatada diferença significativa para a porcentagem de botões atacados pelo bicudo entre os genótipos avaliados (Tabela1) (Fig.1). Resultado semelhante foi obtido por Morales et al. (1997) que, ao avaliarem diferentes genótipos de algodoeiro, observaram que aos 130 DAE todos apresentaram igual incidência de botões florais atacados pelo bicudo.

Analisando os dados da produção, não foi verificada diferença estatística significativa entre os genótipos para a maioria dos parâmetros avaliados, exceto para massa de 100 sementes (Tabela 1) (Fig.2).

VIEIRA et al. (2001) analisaram a produção de 12 variedades de algodão e também não detectaram diferenças estatísticas significativas, entre os genótipos, para nenhuma das características agronômicas e tecnológicas de fibras avaliadas.

Testes de rendimento, com linhas quase isogênicas de algodões de folha vermelha e de folha verde, conduzidos na Luisiânia (EUA), indicaram uma redução de rendimento, significativa e consistente associada à coloração vermelha, variando de $7 \%$ a $30 \%$ (JonEs et al., 1986), contudo no presente trabalho o fator rendi- 
mento não foi significativo para os genótipos avaliados (Tabela 1) (Fig. 2).

Estudo de rendimento, em algodões com folha "okra", demonstrou que este foi aproximadamente igual ao dos algodões de folhas normais (JonEs et al., 1986). Resultados da análise de variância, apresenta- dos na Tabela 1, demonstram que não houve significância para o fator rendimento entre os genótipos avaliados. A linhagem IAC-04/ 489 (folha "okra") não diferiu da linhagem IAC- 04/227 e da cultivar IAC-24 (Fig. 2), ambas com folhas normais, confirmando o mencionado por Jones et al. (1986).

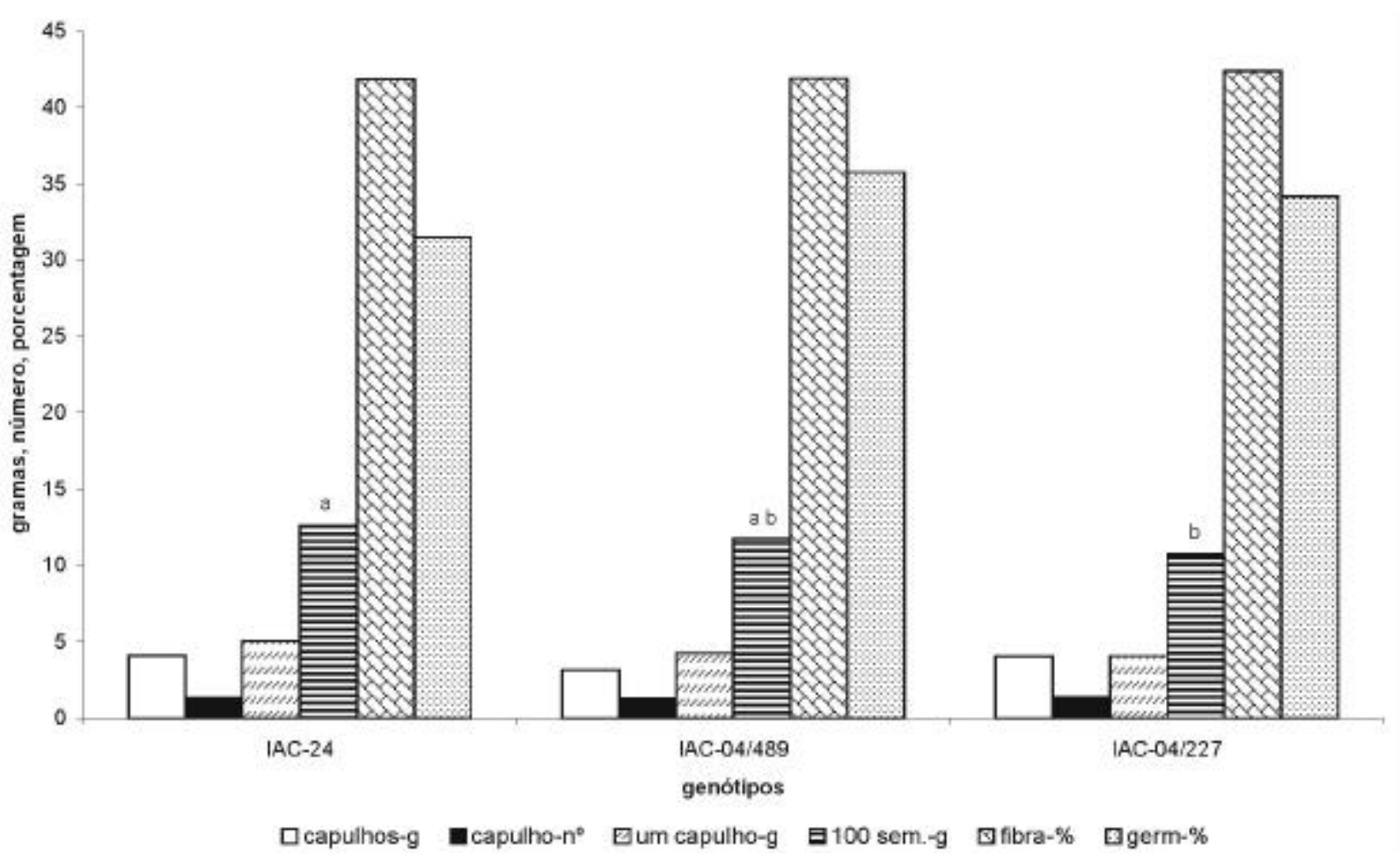

Fig. 2 - Dados quantitativos da produção para diferentes genótipos de algodoeiro. Campinas, SP. 2006.

Tabela 1 - Síntese das análises da variância e teste de médias (Tukey), para as épocas e parâmetros avaliados. Campinas, SP. 2006.

\begin{tabular}{|c|c|c|c|c|c|c|c|c|}
\hline & \multicolumn{8}{|c|}{ Datas das amostragens (DAE) ${ }^{1}$} \\
\hline & 03/01 (64) & 10/01 (71) & 17/01 (78) & 24/01 (85) & $31 / 01(92)$ & $07 / 02(99)$ & $14 / 02(106)$ & $21 / 02(113)$ \\
\hline $\mathrm{F}$ & $12,98^{* *}$ & $16,54^{* *}$ & $16,65^{* *}$ & $20,01^{* *}$ & $9,24^{* *}$ & $4,45^{*}$ & $0,15 \mathrm{~ns}$ & $27,77^{* *}$ \\
\hline $\mathrm{CV}$ & 17,74 & 13,00 & 9,30 & 5,59 & 12,05 & 8,41 & 11,96 & 6,83 \\
\hline \multirow[t]{3}{*}{ DMS } & 12,11 & 9,72 & 7,33 & 4,27 & 11,30 & 8,12 & 11,58 & 6,34 \\
\hline & \multicolumn{8}{|c|}{ Parâmetros avaliados } \\
\hline & \multicolumn{2}{|c|}{$\begin{array}{l}\text { Rendimento algodão } \\
\text { em caroço/ planta (g) }\end{array}$} & $\begin{array}{l}\text { No. capulhos/ } \\
\text { Planta }^{2}\end{array}$ & \multicolumn{2}{|c|}{ Massa capulho (g) } & $\begin{array}{l}\text { Massa de } 100 \\
\text { sementes }(\mathrm{g})\end{array}$ & $\%$ fibra $^{3}$ & $\begin{array}{l}\% \text { germinação } \\
\text { de sementes }{ }^{3}\end{array}$ \\
\hline $\mathrm{F}$ & \multicolumn{2}{|c|}{$0,92 \mathrm{~ns}$} & $1,60 \mathrm{~ns}$ & \multicolumn{2}{|c|}{$3,08 \mathrm{~ns}$} & $7,01^{* *}$ & $0,70 \mathrm{~ns}$ & $0,31 \mathrm{~ns}$ \\
\hline $\mathrm{CV}$ & \multirow{2}{*}{\multicolumn{2}{|c|}{48,72}} & 9,53 & \multirow{2}{*}{\multicolumn{2}{|c|}{18,44}} & 8,56 & 2,54 & 32,19 \\
\hline DMS & & & & & & 1,03 & & \\
\hline
\end{tabular}

${ }^{1}$ DAE: dias após emergência do algodoeiro.

${ }^{2}$ Dados transformados em $\sqrt{x+1}$.

${ }^{3}$ Dados transformados em arc sen.

ns: não significativo.

*significativo a $5 \%$ de probabilidade para o erro experimental.

**significativo a $1 \%$ de probabilidade para o erro experimental. 
Heitholt (1994), trabalhando com plantas de folhas "okra" e plantas de folhas normais em populações de 5,10 e 15 plantas $/ \mathrm{m}^{2}$, observou que o aumento da população de plantas favoreceu a produção de fibra em plantas com folha "okra" e, em contraste, a produção de fibra em plantas normais foi maior nas populações de 5 plantas $/ \mathrm{m}^{2}$. No presente trabalho, com populações de 8 plantas por metro linear, não foi detectada significância, para a porcentagem de fibra, entre as plantas com folhas normais eas plantas com folhas "okra" (Tabela 1) (Fig. 2).

WEAVER JÚNIOR; REDDY (1977) avaliaram linhagens de algodão com caracteres múltiplos para a não preferência pelo bicudo e concluíram que a produção de fibras de algumas linhagens foi igual à testemunha, em testes de produção em que foi feito o controle do bicudoeque foi significativamente maior quando não se aplicou inseticidas.

No presente trabalho, onde não se aplicou inseticidas, a análise estatística não revelou significância para a porcentagem de fibra (Tabela 1) ao contrário do que foi relatado porWEAVER JUNIOR.; REDDY (1977).

Estudos futuros devem ser realizados com a linhagem IAC-04/227, em áreas isoladas e distantes de áreas cultivadas com plantas de coloração verde, a fim de se verificar a estabilidade da não preferência pelo bicudo para esta linhagem, pois a coloração vermelha das plantas é um caráter importante no manejo da resistência do algodoeiro ao bicudo.

A ausência de significância para a maioria dos parâmetros quantitativos da produção permite inferir que a variabilidade entre os genótipos foi relativamente baixa o que aponta para uma elevada proximidade genética entre eles.

\section{AGRADECIMENTOS}

Os autores agradecem ao Dr. Milton Geraldo Fuzatto por ceder o material genético e ao acadêmico de Engenharia Agronômica da UNESP/Botucatu, Thiago Santos Teófilo, pelo auxílio nos trabalhos de campo.

\section{REFERÊNCIAS}

CRUZ, V.R. da Recomendações e experiência de controle do bicudo no Estado de São Paulo. In: DEGRANDE, P. (Ed.). Bicudo do algodoeiro: manejo integrado. Dourados: UFMS. EMBRAPA-UEPAE de Dourados, 1991. p.67-80.
GABRIEL, D.; BLANCO, F.M.G.; MELO, G. de; ROBERG, B.R. Suscetibilidade de genótipos de algodoeiro ao ataque do bicudo Anthonomus grandis Boh., 1843, em condições de campo. In: CONGRESSO BRASILEIRO DE ALGODÃO, 5., 2005, Salvador. Anais. Salvador: EMBRAPA- CNPA, 2005.CD-ROM 1.

HEITHOLT, J.J. Canopy characteristics associated with deficient and excessive cotton plant population densities. Crop Science, v.34, n.5, p.1291-1297, 1994.

ISELY, D. The relation of leaf color and leaf size to boll weevil infestation. Journal of Economic Entomology, v.21, n.4, p.553-559, 1928.

JONES, J.E.; WEAVER, J.B.; SHUSTER, M.F. Plantas resistentes ao bicudo. In: BARBOSA, S.; LUKEFAHR, M.J.; BRAGA SOBRINHO, R. (Ed.). O bicudo do algodoeiro. Brasília: EMBRAPA-DDT., 1986. p.221-249. (Documentos n.4.)

MERKL, M.E.; MEYER, J.R. Studies of resistance of cotton strains to the boll weevil. Journal of Economic Entomology, v.56, n.6, p.860-862, 1963.

MORALES, L.; CENA, P.; MENDES NETO, F.P.; COSTA, S.F.; OLIVEIRA, F.T. de Resistência de genótipos de algodoeiro a Anthonomus grandis Boh., Frankliniella sp. e Aphis gossypii Glover. Anais da Sociedade Entomológica do Brasil, v. 26, n.1, p.93-97, 1997.

STEPHENS, S.G.; LEE, H. S. Further studies on the feeding and oviposition preferences of the boll weevil (Anthonomus grandis). Journal of Economic Entomology, v.54, n.6, p.1085-1090, 1961.

VIEIRA, R. de M.; MEDEIROS, A.A.; GUERRA, A.G.; SANTOS, F.C.dos; BARRETO, M. de F.P. Análise da produção e das propriedades tecnológicas da fibra do ensaio nacional de variedades de algodão. Ipanguaçú RN. 1999. In: CONGRESSO BRASILEIRO DE ALGODÃO, 3., 2001, Campo Grande. Anais. Campo Grande: EMBRAPA-CNPA, 2001. v.2, p.704-706.

VIDAL NETO, F das C.; SILVA, F.P. da; BLEICHER, E.; MELO, F.I.O. Mutantes morfológicos de algodoeiro herbáceo como fonte de resistência ao bicudo. Pesquisa Agropecuaria Brasileira, v.40, n.2, p.123-128, 2005.

WEAVER JUNIOR, J.B.; REDDY, M.S. Boll weevil nonpreference, antibiosis, and hatchability studies utilizing cotton lines with multiple nonpreferred characters. Journal of Economic Entomology, v.70, n.3, p.283-285, 1977.

Recebido em 19/11/07

Aceito em 11/5/09 